\title{
PENGARUH SISTEM PENDAFTARAN ONLINE PENELITIAN DAN KINERJA PANITIA TERHADAP KEPUASAN PENGGUNA
}

\author{
Neng Sri Nuraeni, Yulianti \\ UIN Syarif Hidayatullah Jakarta, Indonesia \\ E-mail: nengsrinuraeni@uinjkt.ac.id
}

\begin{abstract}
The Fast and accurate information is a major requirement in terms of service. Puslitpen as a research institute of the Syarif Hidayatullah State Islamic University (UIN Syahid) Jakarta needs to be supported by a fast and accurate and web-based system. The purpose of this study is to look at the effect of the online research registration system and the committee's performance on user satisfaction. This research refers to Setia, et.al (2011); Nur Subchan, et.al (2012); Gatian, Amy W (1994). The population in this study is the registrar of research assistance proposal for the Research Center for UIN Syahid Jakarta. This study uses cluster sampling in determining the selected sample. The analytical method used is multiple regression. Based on the results of the study showed that the $F$ test results obtained Fcount value of 82.117> Ftable of 3.15 with a significance level of $0.000<0.05$. Because the significance level is less than 0.05 then Ha is accepted, so it can be said that the online registration system and the committee's performance affect the user's satisfaction simultaneously. The contribution of this study has a significant impact on improving the registration system services at the UIN Syahid Research Center in Jakarta.
\end{abstract}

Keywords: online registration system; performance committee; user satisfaction

Abstrak. Informasi yang cepat dan akurat merupakan kebutuhan utama dalam hal pelayanan. Puslitpen sebagai lembaga penelitian Universitas Islam Negeri Syarif Hidayatullah (UIN Syahid) Jakarta perlu didukung oleh sistem yang cepat dan akurat serta berbasis web. Tujuan penelitian ini adalah melihat pengaruh sistem pendaftaran online penelitian dan kinerja panitia terhadap kepuasan pengguna. Penelitian ini merujuk pada Setia, et.al (2011); Nur Subchan, et.al (2012); Gatian, Amy W (1994). Populasi dalam penelitian ini adalah pendaftar proposal bantuan biaya penelitian Puslitpen UIN Syahid Jakarta. Penelitian ini menggunakan cluster sampling dalam menentukan sampel yang dipilih. Metode analisis yang digunakan adalah regresi berganda. Berdasarkan hasil penelitian menunjukkan bahwa dari hasil uji $\mathrm{F}$ diperoleh nilai $\mathrm{F}_{\text {hirum }}$ sebesar 82,117 $>\mathrm{F}_{\text {ubel }}$ sebesar 3,15 dengan tingkat

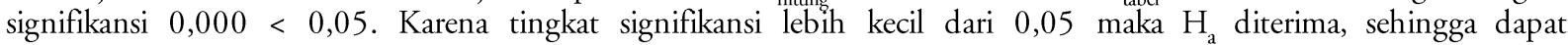
dikatakan bahwa sistem pendaftaran online dan kinerja panitia berpengaruh terhadap kepuasana pengguna secara simultan. Kontribusi penelitian ini berdampak signifikan pada perbaikan layanan sistem pendaftaran di Puslitpen UIN Syahid Jakarta.

Kata kunci: sistem pendaftaran online; kinerja panitia; kepuasan pengguna

Permalink/DOI: https://doi.org/10.15408/mimbar.v36i1.13152 


\section{Pendahuluan}

Sebagai salah satu Universitas Islam terbesar di Indonesia, Universitas Islam Negeri Syarif Hidayatullah (UIN Syahid) Jakarta memiliki kesempatan yang sangat luas untuk mengembangkan posisinya menjadi salah satu Universitas Islam terbesar di mata dunia. Rencana Strategis (Renstra) UIN Syahid Jakarta (2012-2016) adalah milestone pertama dari rangkaian tiga milestones UIN Syarif Hidayatullah Jakarta menuju visi jangka panjang menjadi World Class University pada tahun 2026.

Quacquarelli Symonds (QS), lembaga riset yang bergerak di bidang pendidikan tinggi dalam rilisnya pada 2010 menyebutkan bahwa ada beberapa kriteria inti harus dipenuhi perguruan tinggi di antaranya adalah: (1) kualitas penelitian; (2) lulusan kerja; (3) kualitas pengajaran, dan (4) infrastruktur (Kompas.com, 2016). Kualitas penelitian merupakan kriteria inti pertama menuju world class university.

Dalam upaya melangkah pada tujuan utama UIN Syahid Jakarta menjadikan Kualitas Penelitian menjadi sasaran utama pada tahun 2016. Tema besar yang melatarbelakangi kegiatankegiatan dalam civitas akademika di UIN Syahid Jakarta pada tahun 2016 adalah "Transformasi menjadi Universitas Riset”. Pencapaian kualitas penelitian yang optimal harus didukung oleh beberapa hal diantaranya adalah infrastruktur. Infrastruktur yang baik dapat menunjang layanan kualitas sumber daya manusia yang lemah.

Beberapa tahun belakangan ini, para ilmuan dari pemerintahan maupun badan-badan resmi PBB untuk pelayanan publik terus mengevaluasi dan sekaligus mencari strategi yang tepat dalam meningkatkan standar mutu pelayanan bagi negara-negara berkembang (Slamet dan Cep, 2011).

Pusat Penelitian dan Penerbitan (Puslitpen) merupakan lembaga yang mengelola penelitian di tingkat Universitas Islam Negeri Syahid Hidayatullah Jakarta. Masalah yang dihadapi oleh penyelenggara penelitian UIN Syahid Jakarta dapat diuraikan sebagai berikut:

a) Proses pendaftaran peserta penelitian dilakukan secara manual.

b) Tidak tersedianya data base pendaftar penelitian.

c) Jumlah sumber daya manusia yang melayani terbatas.

d) Pendaftar yang sedang berada di luar kota atau di luar negeri tidak bisa mendaftar penelitian.

e) Terbatasnya Ruang Penyimpanan Dokumen

Untuk mengatasi masalah tersebut diperlukan sebuah system manajemen penyelenggaraan penelitian yang bertujuan :

a) Untuk mengelola para peneliti di UIN Syahid Jakarta dalam sebuah system yang terintegrasi;

b) Untuk mengelola prosedur pendaftaran penelitian, status calon peneliti, dan hasil penilaian secara transparan;

c) Untuk memberikan layanan publik yang optimal;

d) Membantu proses pendataan peneliti.

Sistem manajemen berbasis informasi yang cepat dan akurat sangat diperlukan. Puslitpen app merupakan sebuah system produk layanan berbasis web dan secara online untuk pendaftaran penelitian pada Pusat Penelitian dan Penerbitan (Puslitpen). System ini berusaha memenuhi kebutuhan dosen dan 
mahasiswa untuk dapat melaksanakan pendaftaran penelitian dengan menyediakan fitur otomatis dengan menggunakan media internet. Pengefektifan puslitpen app dapat menjadi sebuah aplikasi yang penting apabila penggunaannya beriringan dengan kualitas kinerja panitia yang baik. Puslitpen app bertujuan untuk mempermudah proses pendaftaran sehingga perlu dikaji apakah aplikasi yang telah ada tersbut dapat membentuk kepuasan pengguna. Hal ini seiring dengan feed back yang penting untuk Puslitpen.

\section{Sistem Pendaftaran Online Penelitian}

Sistem adalah suatu jaringan kerja terdiri dari elemen - elemen yang saling berhubungan untuk melakukan suatu kegiatan dan menyelesaikan tahapan yang akan dicapai. Tujuannya adalah untuk memperbaiki berbagai fungsi didalam yang sedang berjalan agar menjadi lebih efisien, mengubah sasaran sistem yang sedang berjalan, merancang atau mengganti output yang sedang digunakan untuk mencapai tujuan. (Ladjamudin, 2005). Pendaftaran dalam bahasa Indonesia merupakan kata dasar dari kata daftar yang berarti catatan sejumlah nama atau hal yang disusun berderet dari atas ke bawah. Namun arti dari kata pendaftaran itu sendiri berbeda dengan kata dasarnya. Pendaftaran merupakan proses atau cara dari perbuatan mendaftar misalnya pencatatan nama, alamat, dsb.

Proses pendaftaran dalam sebuah kegiatan akan menghasilkan data yang menjadi entitas dalam kegiatan tersebut. Data yang dihasilkan pada proses pendaftaran akan diolah untuk menjadi sebuah informasi yang dapat digunakan untuk proses selanjutnya, pada umumnya informasi yang sudah diproses akan menghasilkan sebuah keputusan atau ketetapan yang berpengaruh dalam sebuah kegiatan (Decision Support System).

Penelitian sebagai salah satu unsur utama dalam Tri Dharma Perguruan tinggi menjadi kegiatan yang wajib diselenggarakan secara berkelanjutan bagi seluruh Perguruan Tinggi di Indonesia. Pusat Penelitian dan Penerbitan (Puslitpen) UIN Syarif Hidayatullah Jakarta dalam hal ini adalah unit atau pusat yang bertanggungjawab penuh terhadap kegiatan penelitian di lingkungan UIN Syarif Hidayatullah Jakarta.

Sebelum tahun anggaran 2016, kegiatan penelitian dalam proses pendaftarannya masih dilakukan dengan sistem manual, dimana dosen membuat proposal penelitian dan lampirannya yang sudah mereka buat dan dicetak untuk kemudian diserahkan kepada Puslitpen guna didaftarkan dalam kegiatan Bantuan Biaya Penelitian sampai dengan tenggat waktu penutupan pendaftaran yang sudah ditetapkan. Setelah semua proposal penelitian dosen terkumpul kemudian dilakukan proses input data secara manual dimana selanjutnya keseluruhan data yang sudah di input akan menjadi menjadi basis data (database) yang akan diolah guna menghasilkan informasi yang selanjutnya dapat menentukan kelulusan dari proposal tersebut.

Proses yang panjang tersebut amat sangat menyulitkan dan melelahkan jika dilakukan secara manual, oleh karena itu menginspirasi kami untuk merintis sebuah aplikasi digital yang dapat memudahkan baik dosen dan tim Puslitpen dalam penyelenggaraan kegiatan penelitian. Puslitpen UIN Syarif Hidayatullah Jakarta, pada tahun anggaran 2016 mulai melakukan perbaikan dalam penyelenggaraan kegiatan Bantuan Dana Penelitian untuk dosen UIN Jakarta. Salah satu aspek yang menjadi fokus dalam perbaikan tersebut adalah mekanisme pendaftaran penelitian bagi para dosen yang mulai dilaksanakan secara daring (Online). 
Pendaftaran Online Penelitian berarti Proses pendaftaran penelitian yang dilakukan melalui komputerisasi yang melibatkan suatu system berbasis Internet. Manfaat Pendaftaran Online antara lain: 1) Memberikan kecepatan pelayanan yang lebih baik; 2) Memberikan kemudahan pendaftaran, karena tidak perlu datang ke instansi yang bersangkutan, asalkan memiliki akses internet; 3)Status pendaftaran dapat diketahui setiap saat.

\section{Kinerja Panitia}

Bernardin dan Russel (dalam Ruky, 2002) memberikan pengertian atau kinerja sebagai berikut : "performance is defined as the record of outcomes produced on a specified job function or activity during time period. Prestasi atau kinerja adalah catatan tentang hasil-hasil yang diperoleh dari fungsi-fungsi pekerjaan tertentu atau kegiatan selama kurun waktu tertentu. Pengertian kinerja lainnya dikemukakan oleh Payaman Simanjuntak (2005) yang mengemukakan kinerja adalah tingkat pencapaian hasil atas pelaksanaan tugas tertentu. Kinerja perusahaan adalah tingkat pencapaian hasil dalam rangka mewujudkan tujuan perusahaan. Manajemen kinerja adalah keseluruhan kegiatan yang dilakukan untuk meningkatkan kinerja perusahaan atau organisasi, termasuk kinerja masing-masing individu dan kelompok kerja di perusahaan tersebut. Menurut M. Blumberg \& C.D. Pringile didalam buku Organizational Behavior oleh (Stephen P. Robbins : 2007), kinerja dipengaruhi oleh tiga dimensi yaitu:

- Dimensi motivasi (Motivation): Indikator yang digunakan untuk mengukurnya: ketepatan pelayanan, kecepatan pelayanan dan tanggung jawab.

- Dimensi kemampuan (Ability): Indikator yang digunakan untuk mengukurnya: keahlian

- Dimensi kesempatan (Opportunity): Indikator yang digunakan untuk mengukurnya: inovatif dan kerjasama

\section{Kepuasan Pengguna}

Kepuasan (Satisfaction) adalah perasaan senang atau kecewa seseorang yang muncul setelah membandingkan kinerja (hasil) produk yang dipikirkan terhadap kinerja (atau hasil) yang diharapkan. Jika kinerja berada di bawah harapan maka pelanggan tidak puas. Jika kinerja memenuhi harapan maka pelanggan puas. Jika kinerja melebihi harapan maka pelanggan amat puas atau senang (Kotler 2006:177).

Kerangka yang digunakan dalam pengamatan kepuasan Pengguna, yaitu mengurai efektifitas Sistem Pendaftaran Online dan kinerja panitia ke dalam lima dimensi (diadopsi oleh para peneliti dari konsep SERQUAL pada kajian pemasaran yang kemudian diujicobakan dalam konteks sistem informasi), ada lima dimensi yaitu: kehandalan (realibility), tanggapan (responsiveness), jaminan (Assurance), tampilan (Tangible) dan empati (Empathy).

\section{Metode}

Penelitian ini menggunakan metode deskriptif, yaitu metode yang bertujuan memberikan gambaran masing-masing variabel yang diteliti dan menggali keterkaitan masing-masing variable. Pendekatan yang digunakan adalah kuantitatif. Menurut Sugiyono (2013:13), pendekatan kuantitatif 
dapat diartikan sebagai metode penelitian yang berlandaskan pada filsafat positivisme, digunakan untuk meneliti pada populasi atau sampel tertentu, teknik pengambilan sampel pada umumnya dilakukan secara random, pengumpulan data menggunakan instrumen penelitian, analisis data bersifat kuantitatif/statistic dengan tujuan untuk menguji hipotesis yang telah ditetapkan. Dilihat dari tujuannya, penelitian ini merupakan penelitian kausal, yang bertujuan untuk menganalisis pengaruh variabel-variabel independen.

\section{Hasil dan Pembahasan}

\section{Hasil Koefisien Persamaan Regresi Linier Berganda}

Analisis regresi linier berganda digunakan untuk mengetahui pengaruh antara variabel independen terhadap variabel dependen, adapun hasil uji regresi linier berganda adalah sebagai berikut:

Tabel 1. Hasil Koefisien Persamaan Regresi Linier Berganda Coefficients ${ }^{\mathrm{a}}$

\begin{tabular}{lllll} 
Model & & \multicolumn{2}{l}{ Unstandardized Coefficients } & \multicolumn{2}{l}{ Standardized Coefficients } \\
& & B & Std. Error & Beta \\
1 & (Constant) & -2.017 & 1.413 & \\
& SPO & .278 & .035 & .641 \\
& KPA & .159 & .042 & .310
\end{tabular}

a. Dependent Variable: KPE

Sumber: data primer yang diolah

Berdasarkan hasil yang telah diperoleh dari koefisien regresi di atas, maka dapat dibuat suatu persamaan regresi sebagai berikut:

$$
Y=-2,017+0,278 X_{1}+0,159 X_{2}
$$

Pada persamaan regresi di atas menunjukkan nilai konstanta sebesar $-2,017$. Hal ini menyatakan bahwa jika variabel sistem pendaftaran online dan kinerja panitia dianggap konstan atau bernilai 0 (nol), maka kepuasan pengguna akan menurun sebesar -2,017 satuan atau -20,17\%.

Koefisien regresi pada variabel sistem pendaftaran online sebesar 0,278, hal ini berarti jika variabel sistem pendaftaran online bertambah satu satuan maka variabel kepuasan akan meningkat sebesar 0,278 satuan atau 27,8\%, dengan catatan variabel lain dianggap konstan.

Koefisien regresi pada variabel kinerja panitia sebesar 0,159 , hal ini berarti jika variabel kinerja panitia bertambah satu satuan maka variabel kepuasan pengguna akan meningkat sebesar 0,159 satuan atau $15,9 \%$, dengan catatan variabel lain dianggap konstan.

\section{Hasil Uji Hipotesis Penelitian}

\section{Hasil Uji Secara Parsial (Uji t)}

Uji statistik t berguna untuk menguji pengaruh dari masing-masing variabel independen secara parsial terhadap variabel dependen. Untuk mengetahui ada tidaknya pengaruh masing-masing variabel independen secara parsial terhadap variabel dependen dapat dilihat pada tingkat signifikansi 0,05 . Hasil 
uji statistik t dapat dilihat pada tabel 4.14, jika nilai signifikan $<0,05$ maka $\mathrm{H}_{\mathrm{a}}$ diterima, sedangkan jika nilai signifikan > 0,05 maka $\mathrm{H}_{\mathrm{a}}$ ditolak. (Ghozali, 2013:178).

Tabel 2. Hasil Uji Secara Parsial (Uji t) Coefficients ${ }^{a}$

\begin{tabular}{|c|c|c|c|c|c|c|}
\hline \multirow{2}{*}{\multicolumn{2}{|c|}{ Model }} & \multicolumn{2}{|c|}{$\begin{array}{l}\text { Unstandardized } \\
\text { Coefficients }\end{array}$} & $\begin{array}{l}\text { Standardized } \\
\text { Coefficients }\end{array}$ & $\mathrm{t}$ & Sig. \\
\hline & & B & Std. Error & Beta & & \\
\hline 1 & (Constant) & -2.017 & 1.413 & & -1.428 & .159 \\
\hline & SPO & .278 & .035 & .641 & 7.854 & .000 \\
\hline & KPA & .159 & .042 & .310 & 3.800 & .000 \\
\hline
\end{tabular}

Sumber: data primer yang diolah

Berdasarkan hasil pengujian dari tabel 4.15 dapat disimpulkan sebagai berikut:

\section{Pengaruh Sistem Pendaftaran Online terhadap Kepuasan Pengguna}

Hasil uji hipotesis 1 yang ditunjukkan pada tabel 4.15, terlihat bahwa $\mathrm{t}_{\text {hitung }}$ sistem pendaftaran online adalah 7,854, Sedang $t_{\text {tabel }}$ bisa dihitung pada tabel $t$-test, dengan $\alpha=0,05$, karena digunakan hipotesis dua arah, ketika mencari $\mathrm{t}_{\text {tabel }}$, nilai $\alpha$ dibagi 2 menjadi $0,025 \mathrm{dan} \mathrm{df}=60$ (didapat dari rumus $\mathrm{n}-2$, dimana $\mathrm{n}$ adalah jumlah data, $62-2=60$ ). Didapat $\mathrm{t}_{\text {tabel }}$ adalah 2,00030.

Variabel sistem pendaftaran online memiliki nilai sig. $(0,000)<0,05$ artinya signifikan, sedangkan $t_{\text {hitung }}>t_{\text {tabee }},(7,854>2,00030)$, Hal ini berarti $\mathrm{H}_{a 1}$ diterima sehingga dapat dikatakan bahwa sistem pendaftaran online berpengaruh positif dan signifikan terhadap kepuasan pengguna, hal ini menunjukan bahwa semakin baiknya sistem pendaftaran online maka akan semakin meningkatkan kepuasan pengguna. Hasil penelitian ini konsisten dengan penelitian yang dilakukan oleh Wardani, Rosidi dan Fattah (2011) yang menyatakan bahwa terdapat pengaruh yang signifikan antara efektifitas SIAP-PSB online terhadap kepuasan user. Subchan, Astuti dan Kertahadi (2012) menyatakan bahwa terdapat pengaruh langsung dan tidak signifikan antara dimensi kualitas informasi terhadap kepuasan pengguna portal akademik. Amy W (1994) menyatakan bahwa terdapat pengaruh antara efektifitas sistem terhadap kepuasan pengguna.

\section{Pengaruh Kinerja Panitia terhadap Kepuasan Pengguna}

Hasil uji hipotesis 2 yang ditunjukkan pada tabel 4.15, terlihat bahwa $t_{\text {hitung }}$ kinerja panitia adalah 3,800, Sedang $t_{\text {tabel }}$ bisa dihitung pada tabel $\mathrm{t}$-test, dengan $\alpha=0,05$, karena digunakan hipotesis dua arah, ketika mencari $t_{\text {tabel }}$, nilai $\alpha$ dibagi 2 menjadi 0,025 dan $\mathrm{df}=60$ (didapat dari rumus $\mathrm{n}-2$, dimana $n$ adalah jumlah data, $62-2=60$ ). Didapat $t_{\text {tabel }}$ adalah 2,00030.

Variabel kinerja panitia memiliki nilai sig. $(0,000)<0,05$ artinya signifikan, sedangkan $t_{\text {hitung }}>$ $\mathrm{t}_{\text {tabel }},(3,800>2,00030)$, Hal ini berarti $\mathrm{H}_{\mathrm{a} 2}$ diterima sehingga dapat dikatakan bahwa kinerja panitia berpengaruh positif dan signifikan terhadap kepuasan pengguna. Hal ini menunjukan bahwa semakin baiknya kinerja panitia maka akan meningkatkan kepuasan pengguna. Hasil penelitian ini mendukung penelitian Wardani, Rosidi dan Fattah (2011) yang menyatakan bahwa terdapat pengaruh yang signifikan antara kinerja panitia terhadap kepuasan user. 


\section{Hasil Uji Secara Simultan (Uji F)}

Hasil uji statistik $\mathrm{F}$ dapat dilihat pada tabel di bawah ini, jika nilai probabilitas lebih kecil dari 0,05 maka $\mathrm{H}_{\mathrm{a}}$ diterima dan menolak $\mathrm{H}_{\mathrm{o}}$, sedangkan jika nilai probabilitas lebih besar dari 0,05 maka $\mathrm{H}_{\mathrm{o}}$ diterima dan menolak $\mathrm{H}_{\mathrm{a}}$.

Tabel 3. Hasil Uji Secara Simultan (Uji F) ANOVA ${ }^{a}$

\begin{tabular}{|c|c|c|c|c|c|c|}
\hline \multirow{2}{*}{$\begin{array}{l}\text { Model } \\
1\end{array}$} & & Sum of Squares & $\mathrm{df}$ & Mean Square & \multirow{3}{*}{$\begin{array}{l}\mathrm{F} \\
82.117\end{array}$} & \multirow{2}{*}{$\begin{array}{l}\text { Sig. } \\
.000^{b}\end{array}$} \\
\hline & Regression & 451.627 & 2 & 222.813 & & \\
\hline & Residual & 162.244 & 59 & 2.750 & & \\
\hline & Total & 613.871 & 61 & & & \\
\hline
\end{tabular}

Sumber: data primer yang diolah

Berdasarkan tabel di atas menunjukkan bahwa dari hasil uji $\mathrm{F}$ diperoleh nilai $\mathrm{F}_{\text {hitung }}$ sebesar $82,117>\mathrm{F}_{\text {tabel }}$ sebesar 3,15 dengan tingkat signifikansi $0,000<0,05$. Karena tingkat signifikansi lebih kecil dari 0,05 maka $\mathrm{H}_{a}$ diterima, sehingga dapat dikatakan bahwa sistem pendaftaran online dan kinerja panitia berpengaruh terhadap kepuasana pengguna secara simultan.

\section{Saran-Saran Peneliti}

Dari hasil penelitian ditemukan fakta bahwa para peneliti banyak memberikan saran dan masukan untuk puslitpen dalam rangka peningkatan kualitas pelayanan. Diantaranya adalah :

- Untuk Sistem Pendaftaran Online: 1) Para peneliti merasa kesulitan saat mengupload file proposal dan persyaratan lainnya; 2) System pendaftaran online butuh penyempurnaan; 3)Para peneliti meminta untuk diadakannya monitoring secara online. 4) Sosialiasasi system pendaftara online lebih jelas; 5)System pendaftaran harus terintegrasi dengan E-LKP dan AIS; 6) Fitur harus lebih menarik dan mudah dipahami

- Untuk Kinerja Panitia: 1)Panitia harus bersikan ramah dan menerapkan 3 S (senyum, sapa, salam); 2) Panitia harus ada ditempat pada saat pengumpulan laporan; 3) Adanya pelayanan konsultasi online; 4)Panitia harus cepat tanggap dan memberikan pelayanan yang ramah.

- Untuk Kepuasan Pengguna: Dari keseluruhan saran para peneliti, rata-rata para penelitia masih merasa belum puas terkait dengan system pendaftaran online penelitian dan kinerja panitia.

\section{Penutup}

Berdasarkan uraian yang telah dijelaskan maka Simpulan yang dapat diambil adalah sebagai berikut:1)Sistem pendaftaran online berpengaruh postif terhadap kepuasan pelanggan. Hasil penelitian ini sesuai dengan penelitian Wardani, Rosidi dan Fattah (2011); Subhan, Astuti dan Kertahadi (2012); Amy W (1994); 2) Kinerja panitia berpengaruh positif terhadap kepuasan pelanggan. Hasil penelitian ini sesuai dengan penelitian Wardani, Rosidi dan Fattah (2011); 3) Sistem pendaftaran online dan kinerja panitia berpengaruh positif terhadap kepuasan pengguna. Hasil penelitian dengan penelitian Wardani, Rosidi dan Fattah (2011). Dan rekomendasi yang diharapkan dari penelitian ini: 1)Untuk penelitian selanjutnya untuk menambahkan jumlah responden; 2)Adanya penggunaan variabel yang 
lain seperti efektifitas pelayanan; 3) Puslitpen harus memperbaiki system pendaftaran online dan kinerja panitia, berdasarkan saran dan masukan dari para dosen peneliti.

\section{Daftar Pustaka}

Bahra Bin Ladjamudin, 2005, Analisis dan Desain Sistem Informasi, Yogyakarta, Graha Ilmu.

Gatian, Amy W. 1994. Is User Satisfaction a Valid Measure of System Effectiveness?. Research Information \& Management. 26.119-131. North Holland

Kompas.com, 2016. Ini Syarat Menjadi “World Classs University”.Di akses pada 24

Kotler, Philip. 2006. Manajemen Pemasaran, Edisi Pertama. Indonesia: PT. Indeks Kelompok Gramedia.

Nur Subchan, Endang Siti Astuti, Kertahadi. 2012. Mengukur Efektifitas Sistem Informasi dan Mengetahui Kesuksesan Portal Akademik (SIAM) Online (Studi Kasus terhadap Pengguna di Program Pendidikan Vokasi Universitas Brawijaya). E-Jurnal Fakultas Ilmu Administrasi Universitas Brawijaya Vol. 6, No. 2

Rencana Strategis UIN Syarif Hidayatullah Jakarta (2012-2016)

Robbins SP, dan Judge. 2007. Perilaku Organisasi, Jakarta : Salemba Empat

Ruky. , Ahmad. 2002. Sistem Manajemen Kinerja. Jakarta : Gramedia Pustaka Utama.

Setia Wardani, Abidarin Rosidi, Hanif Al Fatta. 2011. Analisis Efektifitas SIAP-PSB Online dan Kinerja Panitia terhadap Kepuasan User di Wilayah Dinas Pendidikan Kota Yogyakarta. Jurnal Teknologi. Volume 4 No. 1

Simanjuntak, Payaman J. 2005. Manajemen dan Evaluasi Kerja. Lembaga Penerbit FEUI, Jakarta.

Slamet Riyanto dan Cep Adiwiharja. 2011. Sistem Manajemen Pendaftaran Diklat Peneliti Secara Online. https://www.researchgate.net/publication.

Sugiyono. 2013. Metode Penelitian Pendidikan Pendekatan Kuantitatif, Kualitatif, dan R\&D. Bandung: Alfabeta. 